\title{
Visionary Leadership: What, Why, and How
}

\author{
Dedy Hermanto Karwan ${ }^{1}$, Hasan Hariri², Ridwan Ridwan ${ }^{3}$ \\ \{dedy.karwan@fkip.unila.ac.id ${ }^{1}$, hasan.hariri@staff.unila.ac.id², \\ ridwanrosidimuawai@gmail.com ${ }^{3}$ \} \\ Master of Educational Administration, University of Lampung, Bandar Lampung, Lampung, \\ Indonesia ${ }^{1,2}$, SMP Negeri 3 Way Pengubuan, Lampung Tengah, Lampung, Indonesia ${ }^{3}$
}

\begin{abstract}
This study examines how principals practiced visionary leadership with all its dynamics. We studied what, why, and how visionary leadership emerges. This research used a literature review from selected articles. This research examined the leadership of principals from the visionary leadership studies domain. The journal articles, which are reviewed, are from which have functioned to become as major outlets for visionary leadership research by principals and in a wider area within the scope of education to gain awareness of the increasing need for visionary leader importance in some of the research findings in the field. The authors concluded that (1) visionary leadership is leadership behavior that has personal characteristics and the ability to see holistically to create, articulate, interpret, imagine, and communicate, reinterpret school goals to followers to achieve school goals as a form of school anticipation of changes in the future. (2) visionary leadership is enlightening, therefore something good should be done properly as well as action a complete human being as a human being with its human values, and (3) visionary leadership throughout each country tailored to such characteristics as ideological, political, economic, social, and cultural respectively aspects.
\end{abstract}

Keywords: principal's leadership, visionary leadership, and practice.

\section{Introduction}

The leadership of Visionary is as important visionary behavior of leadership and individual attribute that need to demonstrate by a leader to have a constructive effect on an institution [1]. Successful principals own the ability to see. Leaders like to believe in the designation of the coming time and not just for the time being [2].

In the trading field, the future sight is a statement of a leader's ideology about the long-run future intended for an institution. A vision explains the dreamed future that a principal needs to create, and is formed in what is called a sight statement. Most sight statements aimed to get on the planned timetable; preferably, they intended to chase or carry out a single day in the end. Vision often told through real cases, recitals, or comparisons that legibly illustrate the intended long-run situation. For instance, the sight statement of one florist is that he does not trade flowers they trade beauty [3]. Quick alter, growth, and organizational success in the common sector depend on the leader as an important person in expanding success for the organization. Leadership is an essesntial key factor in msking an organization's success or failure. Organizational success does not depend on stages, habit, technique, engineering, and 
management by science, but rather because of the leaders role with both sight and capacity to make their coming time [4].

Behavior of visionary leadership exeeds beyond developing sight and transmition and shift across theories leadership. Visionary leadership has a constructive impact on members outcomes, yielding in top trust in leaders, top devotion to leaders, top grade of work among members, and top thoroughly institutional work [5], [6], [7], [8]. Visionary leadership growed from broad leadership of transaction, including leadership of charismatic, and leadership of culture [9]. The five visionary leadership principles are 1) heads do, challenge work, create change, and increase follwers in owning new initiatives and challenging thought. 2) Inspirational motives and enthusiasm by growing a distributed vision with followers; 3 ) advancement of teamwork and support of followers; 4) set as a examplery for followers; 5) major successes in enthusiasm working.

Bennis [10] states four leadership competency needs by each organization, including 1) environmental context and people who understand reason; 2) linking the creation of relationships within and between organizations; 3 ) vision to draw an acceptable picture in the future, 4) finding the development of new guidelines to achieve the vision [11].

Among educational stakeholders, there is much speculation about nature, efforts, attributes, and behaviors that signalize successful leaders. Historically, leadership is as a thought has investigated, reinterpreted, and redefined in schooling [12]. Distinguished practices of leadership and ideology have generated notice and dispute among chairman who recognizes and connects themselves to particular approaches to leadership.

This study, the principal's leadership, examined from the domain of visionary leadership studies. The journal articles, which the authors reviewed, are from which have functioned to become as major outlets for visionary leadership research by principals and in a wider area within the scope of education to gain awareness of the increasing need for visionary leader importance in some of the research findings in the field.

An examination of visionary leadership articles and practicing perceptions of principals' leadership is implicit in the conceptualization of this study. The articles can be quantitative, survey, and qualitative methodologies used to illustrate the practice of the principal of the visionary leadership and to explain the array of their visionary leadership in the description. The authors posed the following research questions:

1. How did the researches define visionary leadership?

2. How does visionary leadership matter?

3. How did the principals implement in schools?

\section{Methodology of Research}

A search made to identify published articles, which examined the practice of visionary leadership, by school principals. We used Google Scholar electronic databases that collectively cover a large span of management journals and journal of application of psychology. We include words and their combinations to form search phrases from the words visionary, principalship, education, and school. This process produced seven journal articles, which we deemed necessary from search with yield covering dissertations, conference papers, journal articles, books, and processes, and working papers with various approaches, both qualitative, quantitative, and serving. From this category, we explored to be able to answer the research questions that we had compiled. 


\section{Results of Research}

We present the results include Visionary Leadership Attitude, Visionary Leadership and the Future, Principals' Attitudes toward Visionary Leadership, Visionary Leadership Development in Practice, Visionary Leadership of School Principals in Public Middle School, and Visionary Principal's Leadership and Reading Performance,

\subsection{Visionary Leadership Attitude}

Several education administration professors examined the content validity of the 56 -item instrument. The piloting instrument consisted of 24 visionary items with the strongest agreement response patterns, and 11 management items with the strongest dissent, maintained for the revised instrument. These items preserve the findings because they maximize the difference between the visionary and management categories. The number of vision items exceeds the number of management items because the measurement of attitudes towards visionary leadership was the aim of this instrument. The Cronbach's formula used to estimate internal consistency produces an alpha coefficient of 0.87 on the vision items used in the pilot study. The result was a reliability coefficient, as predicted by Cronbach's alpha, for the visionary and management subscales of 0.65 and 0.55 , with 0.65 for the total instrument. The coefficients for the five visionary subscales were $0.31,0.57,0.63,0.54$, and 0.53 [13].

All data were subjected to a series of factor analyzes. The initial factor analysis, using management and the visionary five subscales as variables, was the analysis of the main components using the SAS FACTOR procedure (SAS FACTOR was software that performed various general and rotational factors and component analysis). Estimates of one similarity were used, and there were no eigenvalues (each of a set of parameter values whose differential equation has a zero solution) under certain specified minimum conditions. The eigenvalue, or amount of variance explained by each of the six factors, was $2.94,0.89,0.69,0.52,0.49$, and 0.47 . For this principal component analysis, a loading factor of 0.7 or greater is considered prominent. The interpretation of these factors was rather clear. All vision subscales were strongly contained in the first factor, and management subscales were strongly contained in the second factor [13].

To further strengthening the two-factor vision and management solution, a second major component factor analysis was carried out using all 35 items as variables. Again, similarity estimates were used, and no minimum eigenvalue was specified. Because only two factors were interpreted, the eigenvalues for factors one and two were 5.80 and 2.14, respectively. For the analysis of these main components, loading factors of 0.25 or greater were considered sufficient. Factor loading for principal component analysis used 35 items as variables.

Of the eleven management items, nine were included on management factors, one (item 9) was loaded on vision factors, and one (item 16) was loaded on both factors. These items must be revised or removed from the instrument. Two items were loaded on both management and vision factors. One (item 5) contains higher management factors and was an acceptable management item. The others (item 18) were loaded higher on the vision factor and must be revised to reduce ambiguity. All 24 vision-items were included in the vision factor, although four items $(21,27,29$, and 32) were also included in the management factor. In all four cases, the higher loading was on the vision factor as expected. Several explanations made sense for double loading. This analysis showed the overlap between management's vision and conceptualization, especially in terms of commitment to school goals. Besides, loading could suggest alternative interpretations of the intended meaning of the selected term. For example, 
some respondents could conceptualize adult males as leaders who created new ideas or took risks in the context of their administrative duties. However, the item was intended to describe proactive leadership [13].

Researchers sought to further refine and expand the visionary style to support the five dominant attributes of visionary leaders, two additional rotational factor analyzes were carried out. However, very few loading factors that reached criteria 0.25 or greater than this solution could not be maintained. Therefore, leadership seemed to fall into two categories, managerial and visionary, and further subdivisions of the visionary style were unwarranted [13].

The analysis of attitude instruments designed by the researchers described in this study showed that the ideal conceptualization of visionary leadership needed further exploration. Two factors were maintained to support researchers' speculation that visionary attributes were conceptually different from managerial qualities, although both could be demonstrated by a practicing leader. Further classification of items into classes corresponding to dominant visionary attributes was not supported by factor analysis. Some items were ambiguous and must be reconsidered. Further improvements were needed to improve the accuracy of instrument measurements. However, the development of exploration and analysis showed that it had potential as a tool for the assessment of attitudes towards the conception of leadership labeled visionary.

Given the advocacy supported by research for dynamic leadership that correlates with changes in schools, there were timely and relevant instruments. Providing a variety of valid methods for assessing individual leadership trends would be very helpful for diagnostic purposes. The candidate's attitude to enroll in a leadership preparation program could be assessed as one of the many data sources for screening procedures. Variations between individual perceptions about the role of leadership could become clear through the use of a series of diagnostic procedures. Those who showed a tendency to accelerate change were promising candidates for preparatory programs and for recruitment or promotion in districts that support education restructuring.

Data from attitude assessment could be used to plan and modify teaching programs according to the needs indicated. Preparatory programs could be designed to take advantage of existing attitudes or encourage perceptions of new leadership. Professional development experience could be individualized to improve the visionary abilities to practice school leaders. The mandate to empower visionary leaders was urgent given the demands for successful reforms in schools [13].

\subsection{Visionary Leadership and the Future}

Placing a sight was not only a new path to say placing goals or long-run preparation. This was the main responsibility for school leaders at this time, and it passed the top in aheadthought, innovative preparation, and group involvement. That's a tough task but not the scary one. Visionary leadership involved 1) a serious assessment of your past and present preparation, your accomplishment, and want to revise goals; 2) identify trends and problems that arise, and thought of their possible effect on approach and agendas; 3) setting aims that could be achieved. Referring to the knowledge and experience, the leader got from the past and the determination of needs in the future; 4) dedication to vision (no body has ever succeeded in doing an effort that was not carried out by people who allied); 5) the involvement of others in developing their vision and empowerment to act on that vision; application; and 6) agreement to do the innovations needed to increase the probale to success [14]. 


\subsection{Wise Visionary advice}

Below are the valuable advices to implement the visionary leadership phases. Disseminating; ask for advice from others and broadcast to get broad participation in developing and implementing a vision. The action was to ensure that leaders consider all alternatives in preparing the school to change and may be able to have the best brand that would resist change. Request what followers thought should be done. Gather information and advice from teachers, school personnel, parents, group members, tragde leaders, and pupils about what could make it better and change could be done. Consider a committees retreated to discuss other possibility and investigate future probabilities.

Being realistic confident; be realistic; new thoughts would lose effect if they were sought to be too forceful. Evaluate your vision with insiders and knowledgeable followers. However, in the end, as far as the vision seemed achievable even if it required extraordinary effort and some luck pauses for it, so don't be afraid to stretch it a bit and go for it.

Looking for support; anticipating all possible in the future to think of everything that might happen is to listen to all the opinions of experts who could be obtained; critically examine conventional wisdom, and arrange various options. The building was a vision statement that flexibility, do not be too specific to avoid actions that do not need. A flexible response process would allow leaders to react more quickly to changes or unexpected events with minimal disruption [14].

Use the ongoing assessment way that you will apply with any new agendas or policy. In terms of your statement sight, you will need to track tendencies and problems that arise to be ready for their influence on the future of the leader. A smart leader does not hold on to the warning to be voiced before reasoning of alternatives and the new array [15].

Acting balanced; acting in balance made the organization very resistant to change. This includes schools but, not as recommended by discussant of the state school system was certainly a denial part. Sometimes rejection could avoid us creating not needed or foolish changes, and could prevent us from responding too quickly and/or inappropriately to the current crisis. However, the same refusal to accept could avoid necessary changes. Often, it was an organizational structure that impeded our capability to react to new requirements. Maybe a review of that structure and some internal reorganization would expand the capacity of the system to receive, even encourage, positive change.

Getting the bottom line wasn't enough; for teachers and school commitee members, the core was, in the long-run producing excellent education and equitable for all students. In the short term, there were many things, including dropout rates, graduation rates, achievement scores, and implementation of education programs and services needed by public school pulpis and their families. Dr. Nanus did not propose that these goals were not very important, but paying attention to short-term results often made it tougher to think strategically. Another instance was home from business to explain the point. Many growing institutions valued their clients as a top prime concern. Their followers are number two, and investors are only the next when making difficult decisions. They understand that if they do the right thing, they would secure the loyalty and support of clients and workers, and appreciation, for investors would follow. But if they anxiety first about the core, they proposed to make decisions that took shortcuts in the market or unsuccessful to involve staff. In the long run, investors would hurt the most [16].

Progressive schools prioritize pupils over teachers and school staff, and third, societal demands. That's the order in which school leaders make difficult choices. School committee members and school supervisors know that making choices will improve students' abilities to 
study and educators to teach. They will earn the trust and support of pupils, school staff, and parents, and gifts for people will join. However, if they are first worried about the yields of the scores, scores, they are statistically more likely to make unhealthy decisions or fail to get support. In the long term, society will hurt the most [14].

Being tough; usually, there are varied ways different to achieve the goals. By encouraging optimal involvement, school personnel and members of the school community in preparing and actuating the vision of the school district, principals will make it possible to distribute ownership of the sight, to accept responsibility for it, and to have a sense of attainment that comes from making it work. However, when leaders encourage involvement, leaders must be prepared and willing to praise people for their initiative and put up with followers' mistakes.

Nanus suggested other benefits that could be obtained from involving others in the procedures. Apart from the energetic features of an approach, it also lets many small experiments and learning experiences occur, and it isolates organizations from large mistakes that will pretty much certainly come behind from top-down planning or supervision [14].

Acting on time; the best time to prepare and to talk about creating growth is when things look their top. It is a very big assignment to propose new choices and try to implement change when difficult times or crises have grown. Nobody wants to talk about a vision for the future or new innovative approaches when there are serious problems. It is important to take the time to expand your school board's vision and implement an ongoing and systematic process that will allow you to respond to changes triggered by outsiders that have the potential to impact your school.

The vision now for the vision would come; the essential of visionary leadership could not be exaggerated. Establishing an educational vision sends back the top of the past and supplies the future. It built on the impression got over decades of experimental programs and at the same time, expressed an increase in the value of education to local communities and the national economic system. It emphasizes students as individuals and as our future leaders. This increased the importance of growing a sense of professionalism and critical value in educators.

It recognized the essence of developing alliances in the education group to give our children a chance to succeed in this tricky global society. This clearly illustrated the role of the local school committee, to help safeguard the nation's freedom, plan the economy for prosperity, and enrich people's lives, all constantly striving to foster excellence and equality in primary and secondary education generally for all pupils [14].

In short, it was visionary leadership. This was a means to achieve the educational mission and local school council that could unite all communities well in our democratic parents' community groups and all other parties who cared about education effectively and responsibly to initiate a vision and buck up the lasting shift in our school [14].

\subsection{Principals' Attitudes toward Visionary Leadership}

One of the characteristics possessed by visionary leaders was having strong personal beliefs and values. Experts had noted that prominent principals were individuals whose commitment to their own beliefs was visible. Visionary principles were proactively aggressive in directing activities in their schools towards the realization of goals that were consistent with their personal beliefs. Educational goals that are personally important for principals were very important in school life because visionary principals were determined to realize their own goals [17]-[19]. 
Schools led by visionary principals and companies led by visionary executives were also characterized by observable manifestations of shared ideology [20]-[22], [18]. Ideological attitudes were manifested in the verbalization, behavior, and interaction of people who were members of the school or organizational culture. There was a clear understanding of shared goals, distribute beliefs and values, and hinged metaphors that appear for the image of the institution. Almost all importantly, followers of culture consciously directed their energy toward the realization of the common age. Visionary leaders recognized the strong influence of ideology and successfully used cultural processes to make distributed ideologies.

Visionary chairman gained a reputation as innovative individuals. They were driven by the wish to make new directions and start new actions in their institution [20]. Their firm orientation to change was completed by the individual image of their institution in the future. The school they envisioned under their leader's ship was specifically better in some ways than it is today. Often, in time, their vision was shown to show prophetic wisdom [20], [17].

Non-visionary leaders, by contrast, were more focused on firmness than change. Their explanation of their leadership focused on preserving the immediate processes needed for daily orders at school [23]. They emphasized the control for continuing school operations rather than the encouragement for envisioning and achieving long-term goals. Wolcott's case study of non-visionary principals explicitly showed managerial concern with direct events and the absence of deliberate action for change or future vision [24].

Because the visionary leadership style had emerged as a prominent principal characteristic, the focus of this research article was on the principal's tendency to think and act in a visionary manner. Principals' attitudes toward visionary leadership were assessed through surveys of practitioners who represented existing leadership [5], [6].

The generalization that good principals had visionary leadership attributes were substituted in previous research. The principals who participated in the studies were generally selected based on an outstanding reputation. This research contributed to a new dimension by measuring the attitudes of more representative groups. There was reason to suggest that, in general, public school principals highly respect visionary leadership. While the question of how principals who responded to employ visionary leadership in their schools was beyond the scope of this study, their positive attitude towards it implies that principals believe in the importance of innovation, a sense of control for their school, and a vision for the time to come $[5]$.

Grady and LeSourd stated that there were inconsistencies between individual responses. For example, some school principals agreed that it was important to do what others expected and disagreed with statements about achieving personal goals at school. However, visionary leaders were characterized by independent decision-making, decisive goal setting, and actions that promoted their vision. Reluctance to impose personal goals could illustrate the differences between public school leaders and company executives. Executives were described as progressive when they regulated the color of the organization by imposing their ideology. Perhaps the role of public services from education influenced the principal to avoid unilateral allies. They surveyed school officials strongly believed in the value of the shared school ideology that stood out but did not necessarily believe that it was their ideology. Data shows that principals had doubts about whether their advantages and trust should be the values and beliefs of school culture [5].

Some school principals agreed that their own beliefs should stand out in a school setting, but they were not forced. Maybe coercion remained coercion and is not pleasant. If so, the question of how principals would make their beliefs stand out comes to mind. Nearly half of the respondents in this study showed a positive attitude towards smooth communication of 
school goals and the articulation of strong school goals. Perhaps they used both choices and did not consider the statement as representative of different leadership characteristics [6].

Finally, the principal agreed that they must do what was necessary to get the results they wanted and, at the same time, achieved what others expected. Group of school principals others opposed both statements. This disagreement could show an unwillingness to lead with a single goal and lead with a reaction. On the other hand, acceptance of both statements could indicate that some school principals were trying to achieve their goals while also pleasing others [5].

\subsection{Visionary Leadership Development in Practice}

Visionary leaders must have the right vision as a guide for staff to work according to directions, counting the rate to have innovations that lead to changes in the time to come. Chairman must have competence in interpreting their sight in order to it could be explicitly known by followers. They must state their sight orally and practical conduct, and had competence in relating to their distinct explication. Requirements by for visionary leaders were: (1) communicate vision, which is caused by organizational comprehension, organizational workers, and the milieu; (2) prejudice-free who can reach the future; (3) competence in creating networks and teamwork, and develop a culture for superb work reinforcement; (4) competence in expanding interactions with people via two-way communication, recognize the importance of community and participation, and; (5) the expansion of reliable individual custom, for example, communicative clearness, selfconfidence, studying failure as someone's impression in developing opportunities, comprehending workers' weak matters and utilize references to increase their solid points [25]-[28].

Visionary school leaders worked in an integrative system by linking vision with determined aims, focusing on holistic views utilizing their tenacity, intentions, and practice. These leaders were visionary and product-oriented and looking at their time to come with the need for a broad vision and imagination for school success. The leaders of vision of school leaders need that they must have competence in deciding the vision appropriately. School leaders must inspire the fabrication of staff, and used the power of incentives to direct their workers to work whilst following the goals set to be successful [29].

Also, school leaders must direct their workers well ahead of conventional thinking, communication, and information transfer frameworks, and develop staff potential continuously to utilize their knowledge and competencies for schools [30], [31], [28], [32].

Through home visits, visionary leadership consists of theoretical consideration of correspondence between the duties and person. The visionary leadership model had determined the primary responsibility of leaders for communicating vision understanding was seeing the way the association will take. This sight must be exact and draw workers to know a obvious time to come. Vision must be transformed into actions that led to real intentions and practical work activities [33].

Learning from Thailand's experience, as a whole, the situation and needs in expanding visionary leadership managers in Thai primary schools were at a great degree. We know that single detail was at a high level. An assessment of the necessity of visionary leadership managers in the Thai primary schools was at the top degree. In view of every facet, every aspect was at the top level. That is by the findings of the study which states that the leader of the new tide of Thai bureaucracy needed training and expanding their leadership in 3 main 
stages: 1) Individual skills, 2) Bureaucratic mastery, and 3) Administrative knowledge. It was found that individual skills, relatively, at a top degree [34].

There was a need assessment for training and development in the following areas: development of teamwork; 2) Problem solving; 3) Creativity; 4) Bargaining; 5) Personality development; 6) Presentation; 7) Communication in what knowledge about the bureaucracy, as a whole, at the level of high [34].

It was an evaluation of the need to develop visionary leadership. The areas were 1)Prudent thinking, 2) Structured thinking, 3) Leadership, 4) Transactional Management, 5) Dispute Adminstration, 6) Crises Management, 7) Capability, 8) Moral Leader, 9) Administration and knowledge management, 10) Risk Administration, 11) Enough economics, 12) Teamwork management, 13) management of Finance, 14) Marketing management, and 15) Innate role and role in development [34].

The executive underwriting centers owned their base of leadership on full guidance, varying from small to medium grades in 12 parts. The following factors were as: (1) Laissezfaire; (2) contingency leadership; (3) progressive passive leadership; (4) participative leadership; (5) Static characteristics; (6) Charismatic behavior; (7) Inspirational development; (8) Intellectual motivation; (9) Individual recognition; (10) The results of satisfaction of leadership; (11) The results of leadership in the particular attempt, and; (12) Ineffectiveness of leadership results [34].

A primary school administrator had a high degree of utterance in decentralized leadership at a high degree. It was no important distinction in decentralized leadership between man and woman leaders, and a various lifetime of leaders. Besides, it was a noteworthy distinction in decentralized authority between leaders working in schools of different sizes, distinction impression in being school leaders, and distinction school degrees at the 0.05 level [35].

The behavior of workers to education was based on the sight and findings of the study. The finding that workers to teaching used their ability to make, disseminate, and practice their sight in terms of involvement, empowerment, hazard, proper connection, reliable growth, student underpin, work commitment, attention and sight investigation all the time, allotment of resources, expert growth for self-growth and group members [36].

The growth of the Program for Leadership of Visionary Leaders in Thai Primary Schools. The Programs were based on 1) historical setting and the significance of the agendas; 2) program aims; 3) design and engineering in growth; 4) program setup; 5) program content and material, consisting of 3 Books, including Book 1; vision formulation, Book; 2 vision communication, and Book 3; the vision of implementation. The time span of training was 169 hours.

The plot and growth techniques covered 1) Tutorial, 2) Independent learning, 3) Excursion studies, and 4)Factual application. For development implementation, four steps are determined for the development process, as follows: Stage 1; Pretest, Stage 2; Development, Stage 3; Integration, and; Stage 4: Post-test. This was corresponding to the studies that proved that there should be variation, and the load should cover a single kind of competence and cover nine units of study. The time span for training was 180 hours equivalent to 5 weeks [37].

The training concentrated on factual practice. The members must assess themselves and be assessed by their supervisor, participants, and co-workers before and after development. There were appropriate criteria for evaluation. This was supported by the finding that the new waved leaders in the Thai administration had their needs for training and development through learning by conducting, for example, the use of case studies, simulations, business games, and role-playing at a high level. The timespan for growth was 2 weeks-1 [34]. 
The participants' needs were at a high degree. This was according to research findings that there are four parts of a competence development program for an elementary school administrator. Section 1: Initiation; Section 2; details in the competency development program for elementary school administrators; Section 3: an effective assessment tool for competency growth programs for primary school leaders in fieldwork studies, and; Section 4: guidelines, provisions, indicators of success in making use of competency development programs [34].

This was carried oy by the study discovering where it found that the program development of professional competence of small schools in 8 units was appropriate and ranged from a high level to the top. It was underpinned by study findings that specified that the operation of growth in the attribute of the administrator of the school leaders included 5 steps: 1) preparation; 2) preparation for evaluation before development; 3) growth; 4) assessment after growth, and; 5) growth. These were all congruent with the research findings said that the leadership of school administrators' small model of development implemented in three phases. Stage 1: the pre-action; Phase 2: actions consisting of (1) in-depth teaching; (2) workshops for 8 meetings, twice a week, making used leadership growth handbooks in 8 bundles, and field research in best practice schools, Stage 3: follow-up by holding conferences and making use of assessment forms from school leaders' leadership [34].

Technics used to improve the school by studying the development of the vision of school administrators. The participation of the vision and practice of vision found that the workshops in the development of the vision of the school administrator might affect expert growth for school leaders who paid attention to preparing for educators, parents, and pupils to involve in the educational operation [38]. The technique was consistent with Lee and Wong's research on Lucent Technologies' leadership growth agendas with application in growing leadership regularly by setting short courses for experience growth, covering complex simulations, and studying with formal groups, covering group problem solving, studying cases, business games, demonstrations, and role-plays [39]. This is underpinned by Thomas's [38] training of techniques for increasing schools by learning the growth of school leader' sight, involvement in increasing the sight, and vision practices, the findings sum up that workshops in increasing the vision of school leaders must focus on preparing, qualifying educators, parents, and pupils to involve in Educational Management, school leaders had the right individual vision, persistence, and right who can decide the way of the school to achieve its aims [34].

The findings of the visionary leadership leaders growth program in primary schools (from the make use of the program).

The program presented three test results from the Chaiyaphum Educational Service as follows:

Knowledge Test Findings in Visionary Leadership from Elementary School Administrators. Their average pretest score was 17.73 or $59.11 \%$ of the full score of 30 . Their average posttest score was 26.00 or $86.67 \%$ of the full score of 30 . It showed that primary school leaders had an outcome of their post-test at a higher than their pretest scores. Also, everyone passed the $80 \%$ criterion. This was under the findings of research studies Chansiri found that: (1) to the participants for self-evaluation, and evaluated by a superordinate, sub-ordinate them, and colleagues, they had a core competency before training (pretest), overall, high level. The post-test mean score was importantly higher than the pretest at the 0.01 level [37].

Evaluation Findings in Visionary Leadership of Elementary School Administrators. Visionary leadership, as an entire, was at a high degree. Post-test, generally, was at a high 
degree. Contrasting of primary school leaders' visionary leadership between posttest and follow-up, found that the primary school leaders' visionary leadership during follow-up was higher than the post-test of primary school administrators' visionary leadership. This underpinned by research findings, which established that, the average score of the highest pretest covering competence 2: ethical administrator and role models. The second succession was competency 10: moral improvement for educators and staff education. For the post-test, the top average outcome was competency 6: organizational management, management structure, and establishment of control to educators and staff education. The second succession was competence 2: ethical administrators, and role models. The feature in the leadership of school administrators, as a whole, was at an average degree. The top average score of each aspect is the relationship between leaders and schoolteachers, the bottom average grade was the growth of vision, and the relationship between school and society. This underpinned by research that discovered that the experimental group had the capability in increasing their leadership at a better top-level than the control group. Also, they had a post-test leadership at a higher degree, which shows that training programs can help participants to had a better leadership growth [40], [34].

Evaluative Findings of Participant Satisfaction in the Leadership Development Program. Visionaries of Leaders in Elementary Schools, overall, every aspect is at a high level. The teachers had contentment in a sample of planned leadership at high levels [40]. This underpinned by a study that discovered that participants had contentment in the program, as a whole and every aspect, at a high level [37]. Assess discoveries on the level of success in the essence competency growth program, as a whole and in every aspect of the 4 facets, were at a high degree. The highest degree of essence competence was the work team. This was by study findings that discover that satisfaction in training was at the highest standard [34].

The outcome of this research specifies the advantages of the application of a visionary leadership growth program counted three benefits [34] namely: (1) the current situation and needed in developing visionary leadership administrators in Thai elementary schools, overall, at a high level, each aspect were. Assessment of visionary leadership needed for administrators at the highest level, and every aspect is at the highest level. (2) The development program for visionary leadership leaders in Thai primary schools comprised of the following program elements. 1) historical background and significance of the program; 2) program goals; 3) designing and engineering in growth; 4) program structure; 5) program content and material, which made up of 3 books, including book 1: vision formulation; book 2: communication vision; book 3: implementation vision. The duration of training was 169 hours.

Outline and growth techniques comprised of 1) Training, 2) Independent study, 3) Field trip studies, and 4) Factual practice. For growth application, 4 steps are determined for the development process as follows: Step 1: Pretest; Step 2: Growth; Stage 3: Integration; Stage 4: Post-test. (3) Findings from the visionary leadership administrator development program in elementary schools. Concerning the discovery of knowledge tests in the visionary leadership of primary school leaders, the average pretest score was 17.73 or $59.11 \%$, from a full score of 30. Their average Posttest score was 26.00 or $86.67 \%$, from the full score of 30 .

This showed that elementary school leaders had their post-test scores at a higher level than the pretest. Besides, each of them could pass the standard specified as $80 \%$. The assessment findings in the visionary leadership of elementary school leaders were at a high level. Post-test, overall, was at the highest level. In comparing the post-test of the visionary leadership of elementary school administrators between the post-test, and follow-up, it found 
that the visionary leadership of primary school leaders during the follow-up period was higher than the post-test of primary school leaders of visionary leadership. Evaluative findings of members satisfaction in the visionary leadership in the leader growth program in primary schools, as a whole, every aspect, are at a high degree [34].

\subsection{Visionary Leadership of School Principals in Public Middle School}

Visionary leaders used vision in their work. Visionary leadership is important; however, there was a lack of research in the context of schools in Indonesia, especially in Lampung schools. Visionary leadership explained as the capability to make and innoculate a clear sight, giving meaning and purpose to the organization [31], [41]. Visionary leaders grow their vision and combined it into a distributed vision with their colleagues. The communicating vision was what empowers people to act. When people did not act, that vision has not been communicated people use up their time searching directions to take, which made them exhausted and unresponsive [7].

Visionary leaders also exhibited confident behavior, pro-social strengths, and organizational abilities for which their followers needed to own science, skills, and abilities to attaint institutional aims goals [42], [43]. Besides, visionary leadership provide a comprehending of personal leadership styles because they were related to the context and effectiveness of the organization [44], [42].

The results showed that visionary leaders are responsible for the growth and success of their organizations [45], [46], [31]. Other researchers reported that visionary leaders could articulate visions, imbue, and empower disciples to get involved and benefit from organizational change and growth. Visionary leadership created high-level unity, loyalty, trust, motivation, and achievement improvement in organizations [47].

Researchers claimed that this happens because vision had a positive effect on the selfconcept of followers; followers become motivated to achieve the vision because they felt meaningful, identified, and believed in their vision and ability to achieve it. Successful transmission from visionary leadership changes the attitudes and outputs of subordinates, which resulted in organizational transformation [48]. Such visionary leader behavior will lead to better relationships with their followers. Also, they made followers sacrifice themselves and stimulate subordinates with individual consideration [8].

This study had revealed the following findings. First, principals in state junior high schools in Lampung Province identified that they demonstrated all seven domains of visionary leadership style: stimulating intellectuals, supporting, adapting, developing organizations, taking risks, building images, and empowering. Second, the findings show that all major visionary leadership domains correlated positively and significantly. The highest relationship was between building an image and adapting, followed by the relationship between supporting and the least relationship was between empowering and intellectually stimulating. Third, these findings indicated that there was no statistically important distinction in the main visionary leadership scores for men and women. This finding showed that their followers could accept visionary leaders. Fourth, the findings indicate that there was no statistically significant difference in the principal's visionary leadership score for certified and uncertified teachers in understanding the principal's visionary leadership [49], [50].

This study had implications for theory, practice, and further research. In terms of implications for theory, this study contributed to adding knowledge to the existing literature emphasizing the identification of domains of visionary leadership and the relationships between domains. Regarding the implications for practice, this research was useful for 
principals as feedback to enhance their effective leadership. Principals who wanted to improve their schools needed to demonstrate a visionary leadership style with all seven domains. This practice would lead to increased school effectiveness in achieving school goals. Finally, in terms of implications for further research, because this study is limited to using quantitative research using survey questionnaires that lead to a limited understanding of phenomena about how teachers felt about their visionary leadership style; thus, further research must be carried out to overcome this limitation using qualitative research, particularly through in-depth interviews or focus group discussions [50].

\subsection{Visionary Principal Leadership and Reading Performance}

Exposure to the following excerpted from research in Florida stating that $\mathrm{s}$ already been long established that the principal sets the indicator for effective schools and that school leadership has a strong influence on the social environment and the learning of students [51]. "The No Child Left Behind" Act (NCLB) of 2001 placed a recently emphasis on school leadership and emphasized the significance of increasing student academic attaintment in the United States. Therefore, school managers in the 21 st century had been named upon to meet instructional leadership standards that were higher than those requested by school principals in the 1990s [52]. They were also demanded to be increasingly focused on helping teachers and students who had low performance and failed to achieve success.

The scarcity of factual researchs had roamed the influence of visionary principals on student reading performance [53]. Although much had been written about the principal's vision, the use of factual validation to probe the relationship between visionary leadership conduct, visionary leadership attributes and thegrowth of visionary practice and student reading performance had been restricted. Several researces if any, had explored the relationship between principals' attributes and standardized test scores [54]. Although there were some advances in the field of research in school successfulness theory, experts have mentioned the rare of research that explored the relationship between leadership and student achievement [55].

Thees findings in this study had been extended to Sashkin's visionary leadership theory and the ability of leaders to influence educational production. Further research ratified that increasing pupils academic attainment requires school head to produce specific responsibilities and had leadership conducts and characteristics that positively influenced school civilization [56]. In this study, a statistically important connection was reveled between the visionary leadership conduct of primary school principals and reading attainment in class 4 and 5, but not in class 3 . The shortage of a relationship between the primary school head and reading achievement in grade 3 could show that teaching and learning was a complex practise. Some elements affected pupils educational performance. School financial resources, teacher impression, cooperation, and garde of instruction could affect puplis attaintment [57]. However, it was the major authority to encourage cooperation, inspect educator's teaching practices, compensate educators for performance, and encourage a taste of distribute responsibility [58].

Besides, the relationship between primary school principal visionary practise growth and reading achievement provided factual evidence that could help and promote headmasetes to get more knowledgeable about how school leaders could affect pupils educational perfromance circumstancially by means of their affect on the condition of school institution and quality instruction [59], [60]. 
It was estimated that the outcome of this research can be useful for state primary school heads in making use of leadership application that could increase reading performance. Few people might debate that visionary leadership was not a obligatory part for improving school reading agendas. However, principals' understanding of reading programs, together their capability to act as instructional and visionary manager, could enable them to affect school reading programs and increase student reading test outcome [54]. Instructional leadership appears to create a cosiderable effect on student outcomes than leadership of transformational [61]. Ylimaki [62] appointed that further study was needed to investigate the leadership of visionary role of headmasters in a underpinned territory [62].

One limitation of this study was to participate in the voluntary nature of investigators and the extent to which the principal gave an honest response to the survey items. An additional restriction in this inquiry was only $32 \%$ of 75 state elementary school headmasters had been in their schools for minimum a year or more [63].

Other restriction was that sate primary school principals from one Florida school district chose to involve in this research. For that reason, the oucome could only conclude to other sate schools in the districts. It was with the same demographics as those involving in this research. The outcomes were also restricted by the time of the school year in which primary school headmasters asked to finish the Leader Behavior Questionnaire and the span of time they were in their presnt administrative positions. The one-year demand deliberated to respond the needs of headmasters to be able to provide large responses to their school. A choice must make about the time of year that is most good for for the headmaster to answer. They considered in July a less busy period for the headmaster, but that might not be the best time. Finally, this study was limited to pupils in class 3, 4, and 5 who took the Florida Comprehensive Assessment Test reading fro the 2006-2007 accademic years [63].

\subsection{Discussion}

Up to the present time, leadership, innovation, and leadership study have produced complex written work that prevent the comprehension and growth of proof-based application ecommendations. We aim to focus on visionary leadership and more specifically visionary leadership that is practiced in education. Visionary leadership practices in education can be presented from the awareness of individual principals and can also be designed based on a policy called piloting. We discuss our findings concerning our three main objectives below.

\subsection{Research question 1: How do the researches define the principal's visionary leadership?}

They defined that visionary leadership as crucial visionary leadership conduct and individual attributes that need to demonstrate by a head to own a constructive effect on an organization [43]. Successful heads have a sight. The heads like to opine in terms of the time to come and not just for the present time [64].

Visionary leadership is one that sets aims and goal for personal and group action, which does not explain who we are but what we desire or do [65]. Others said to stand apart from the others. Leadership behavior must inspire the sight and connection that sight among followers so that the institution proceed from good to better [66].

Visionary leadership points to the capability to make and connection views about desirable milieu that explain the present situation and promote loyalty to a better time to come. 
Colton [65] portray visionary leaders as people who set aims and objectives for personal and group activities, which do not define what we are but what we ned or do.

Bredeson [23] states that in general understood, vision is the headmaster's capability to holistically see the now, reinterpret the school's mission to all its followers, and make use of imagination and perceptual skills to think beyond the accepted comprehending of what is practical and what which must be quckly applied at present to the time situation for suppotitius ideas and, preferably, future chance.

They defined visionary leadership as the capacity to make and eloquon a clear sight, giving sense and goal to the institution [31], [16], [41]. Visionary leaders expand their sight and combine it into a distributed sight with their followers. connecting sight is what authorize persons to do.

Scholars define visionary leadership differently. However, they agree that visionary leadership is leadership behavior that has personal characteristics and the ability to see holistically to create, articulate, interpret, imagine, and communicate, reinterpret school goals to followers to achieve school goals as a form of school anticipation of changes in the future.

\subsection{Research question 2: Why does visionary leadership matter?}

Principals with visionary characteristics who play moral majors refer to one's tendency to see schools and related projects and studying need not remain so that it might be the opposite and become better. This is the capability to know how things are and how they might not be in perfect terms, but in terms of what is feasible, given the specific school condition [67].

Barth [68] as well highlight the significance of sight in schooling. He debated that sight must regard three powerful reasons: (a) this is the only recipe for school reform that prayed seriously and continuously. (b) This rich insight hammered over years of operation, and (c) excitement working in the school is the result of studying difficult situations and then producing a plan or vision of its own to improve all the things that will achieve.

The statement of Barth [68] validity, content 56-item instrument inspected by some professor had proved statistically. The instruments applied to the pilot project. The statistics proved on Cronbach's formula to estimate the internal consistency coefficient, reliability coefficient, as predicted by Cronbach's alpha, and the coefficients [6].

Researchers sought to further refine and expand the visionary style to support the five dominant attributes of visionary leaders, two additional rotational factor analyzes were carried out. However, very few loading factors that reach criteria 0.25 or greater than this solution cannot be maintained. Therefore, leadership seems to fall into two categories, managerial and visionary, and further subdivisions of the visionary style are unwarranted [6].

The analysis of attitude instruments designed by the researchers described in this study shows that the ideal conceptualization of visionary leadership needs further exploration. Two factors supported researchers' speculation that visionary attributes are conceptually different from managerial qualities, although a practicing leader could demonstrate both. Further classification of items into classes corresponding to dominant visionary attributes did not support factor analysis. Some items are ambiguous and needed to reconsider. Further improvements needed to improve the accuracy of instrument measurements. However, the development of exploration and analysis shows that it has potential as a tool for the assessment of attitudes towards the conception of leadership labeled visionary.

Visionary leadership is important because location wqa vision is not just talking about new ways to say goal setting. Setting goals is a main responsibility for school heads now and it is the best path to pass forward-thinking, innovative preparation, and community 
participation. That is a tough assigment but not the frigthening. Visionary leadership involves six stages. They are 1) a critical assessment of your past and present plans, your attaintment, and the need to reassess goals. 2) Identify trends and problems that arise and consider their possible impact on the plans and agendas. 3) Setting objectives to get based on the science and impression that gained from the past and your intentness of future needs. 4) Loyalty to sight. 5) The involvement of others in developing their vision and empowerment to act on that vision; application, and 6) Readiness to create the changes needed to develope possible for success [14].

The importance of visionary leadership is one of its characteristics that have strong personal beliefs and values. Principals that stand out are individuals whose commitments to their own beliefs are visible. Visionary principles are proactively aggressive in directing activities in their schools towards the realization of goals that are consistent with their personal beliefs. Educational goals that are personally important for principals are very important in school life because visionary principals are determined to realize their own goals [17], [18].

The contrasting visionary leadership of companies and schools is very contrasting. The principal need demanded to be more resilient in influencing his followers. They stated that some school principals agreed that it was important to do what others expected and disagreed with statements about achieving personal goals at school. However, visionary leaders have characters independent decision-making, setting firm goals, and actions that promote their vision. Reluctance to impose personal goals can illustrate the differences between public school leaders and company executives. Executives described as progressive when they regulate the character of the organization by imposing their own ideology. Perhaps the role of public services from education influences the principal to avoid unilateral allies. It is interesting to note that the principals surveyed believed strongly in the value of the shared school ideology that stood out but did not necessarily believe that it was their ideology. The data shows that the princes have some doubts about whether their values and beliefs should be the values and beliefs of the school's culture [5].

Furthermore, the findings of assessment of study in the visionary leadership of primary school leaders are at a high level. Posttest, overall, is at the highest level. In comparing the posttest of the visionary leadership of primary school leaders between the posttest, and followup, it found that the visionary leadership of primary school leaders during the follow-up period was higher than the posttest of primary school leaders of visionary leadership. Evaluative findings of followers contentmen in the visionary leadership in the leader expansion program in primary schools, as a whole, every aspect, are at a high level [5].

Although still in the category of rare, factual researchers have explored the effect of visionary school headmaster on pupil reading attainment [53]. Although researches have written about the principal's vision, the use of factual legalization to probe the connection between visionary leadership conduct, visionary leadership attribute and the growth of visionary culture and student reading performance has been restricted. Some studies, if any, have investigated the connection between principals' attribute and standardized test outcomes [54]. Although there are some advances in the field of study in school successfulness theory, experts have stated the limitation of researches that explore the connection between leadership including visionary leadership and pupils performance [55], [61]. The outcomes of this researchers are in line with the results of the latest research [69] on a qualitative methods type of case study, research stating that the character of students develops in the leadership of the school principal, namely religion, discipline and responsibility carried out in the midday and afternoon prayers in congregation, and Person in Charge. 
This study, a statistically important correlation found between the visionary leadership conducts of primary school headmasters and reading in grades 4 and 5, but not in grade 3 . The shortage of a relations between the primary school headmaster and reading in grade 3 can show that teaching and learning is a complex pahses. Several parts influence performance of student academic. School financial resources, teacher impression, collaboration, and quality of teaching can affect student accomplishment [57]. It is, however, the headmaster responsibility of principals to encourage cooperation, superviseeducator-teaching practices, reward educators for accomplishment, and encourage a sense of distributed responsibility [58].

Even headmasters' knowledge of programs of reading, together their capability to do as teaching and leaders of visionary, can enable them to affect school of reading programs and grow students' reading evaluation outcome [54]. Instructional leadership appers to generate a greater impact on student scores than transformational leadership [55]. Farther study needed to investigate the role of the headmaster's visionary leadership in a underpin milieu [62].

So with that, the authors conclude that visionary leadership is formed and forms a superior person, enlightens, and balances the organization towards and running towards the goals that have been mutually agreed upon. In short, visionary leadership is good and uplifting. Visionary leadership is bright and enlightening. Therefore, principals should do something good and enlightening properly as well as action because it enlightens the goal of the organization of funds to form a complete human being as a human being with its human values.

\subsection{Research question 3: How did the principals implement in schools?}

Visionary leaders guided the right vision as a guide in leading followers to work according to the leadng, including the capability to own innovations that direct to changes in the time to come. Therefore, each country up to the smallest area of the school will take their respective trajectories. The application of visionary leadership from one country to another is not the same, for example, Thailand and Indonesia.

Indonesia's government, nationally, obliged the schools from kindergarten to through college had vision, mission, and objectives of each organization. All institutional stakeholders must understand the organization's vision, mission, and objectives as a compass in carrying out the activities of running the organization to achieve maximum results effectively, and efficiently.

In this regard, leaders must have competence in expalining their vision in order others can explicitly comprehend. They must express their visions orally and practical conduct, and have competence in application their distinct description. The needs for visionary managers are (1) communication sight, which is caused by organizational knowing, institutional staff, and the milieu; (2) nonjudgmental who can reach the future; (3) competence in creating networks and teamwork, and expanding a culture for oustanding performance underpin; (4) competence in growing interactions with people by two-way communication, indetifying the importance of people and followers, and; (5) the growth of reliable personal conduct, for example, communicative explicitly, self-confidence, studying failure as somebody's impressions in growing chances, knowing staff's frail points and utilizing recommendations to grow their strong points [25]-[28].

The application of leadership of visionary in Thailand was through a pilot development project. The development of leadership of visionary administrators in primary schools includes: 1) background of history and importance of the agendas; 2) program objectives; 3 ) design and engineering in expansion; 4) program structure; 5) program content and material, 
consisting of 3 Books, including Book 1; vision formulation, Book; 2 vision communication, and Book 3; the vision of implementation.

Principals who had applied the visionary leadership style documented from the results of a study. This study has revealed the following findings. First, principals in state junior high schools in Lampung Province identified that they showed all seven domains of leadership of visionary style: stimulating intellectuals, supporting, adapting, developing organizations, taking risks, building images, and empowering. Second, the findings show that all major visionary leadership domains positively and importantly correlated. The highest relationship is between building an image and adapting, followed by the relationship between supporting and the least relationship is between empowering and intellectually stimulating. Third, these findings indicate that there are no statistically important differences in the main visionary leadership scores for men and women. This finding shows that their followers accepted visionary leaders. Fourth, the findings indicate that there is no statistically important difference in the principal's leadership of visionary out comes for certified and uncertified teachers in understanding the principal's leadership of visionary.

The author hereby concludes that the implementation of visionary leadership throughout each country tailored to such characteristics as ideological, political, economic, social, and cultural respectively aspects. The implementation process in a country can certainly be emulated by making sufficient adjustments. One thing that encourages findings from Indonesia is that visionary leadership shows excellence including there is no statistically important difference in the main visionary leadership outcome for men and women and no statistically important difference in visionary principals' leadership outcome for certified and non-certified teachers certified in understanding the visionary leadership of the principal. Followers are no longer constrained by income differences but followers are more motivated by visions that can be clearly understood and that is their dream too.

\section{Conclusions}

The study aimed to examine how visionary leadership has been practiced with all its dynamics. The literature reviews from selected articles are used to. In this study, the principal's leadership is examined from the domain of visionary leadership studies. The journal articles which are reviewed are from which have functioned to become as major outlets for visionary leadership research by principals and in a wider area within the scope of education to gain awareness of the increasing need for visionary leader importance in some of the research findings in the field. The authors concluded that (1) visionary leadership is leadership behavior that has personal characteristics and the ability to see holistically to create, articulate, interpret, imagine, and communicate, reinterpret school goals to followers to achieve school goals as a form of school anticipation of changes in the future. (2) visionary leadership is bright and enlightening, therefore something good and enlightening should be done properly as well as action because it enlightens towards the goal of the organization of funds to form a complete human being as a human being with its human values, and (3) visionary leadership throughout each country tailored to such characteristics as ideological, political, economic, social, and cultural respectively aspects. The implementation process in a country can certainly be emulated by making sufficient adjustments.

\subsection{Limitations}


This study is limited to literature review; it does not include field research (qualitative and quantitative method). The strength of this research is that this study can add to the number of researches and particularly knowledge concerning visionary leadership. The limitation of this study expects to trigger researchers to conduct further research.

\subsection{Practical Implications}

Although there are limitations noted, this is something not trivial, we show some of the implications synthesis while for administrator. we suggest two important discovery in this regard that stem that visionary leadership is a lantern for instructional leadership seems to yield a greater effect on student reading outcomes [55]. Ylimaki states that further study needed to explore the visionary leadership role of principals in a encouraging environment [70]. Second, the principal visionary leadership capable of guiding the stakeholders' interests formulates their dreams for the future of the students by way of humanizing an independent stakeholder to contribute to the humanitarian values true and that all of them can be applied to the red carpet for the leadership deploying transformational.

\section{Acknowledgments}

This project supported by the Magister Administrasi of Education Universitas Lampung Faculty of Teacher Training, Universitas Lampung, and funded with DIPA BLU Universitas Lampung. This publication reflects the views of the author, and no Commission responsible for any utilize that may be made of the output contained in.

\section{References}

[1] Sashkin, M., \& Walberg, H. J. (1993). Educational Leadership and School Culture. ERIC.

[2] Smylie, M. A., \& Hart, A. W. (1999). School leadership for teacher learning and change: A human and social capital development perspective. Handbook of research on educational administration, 2, 421-441.

[3] Peters, T. J., \& Peters, T. (1987). Thriving on chaos: Handbook for a management revolution: Knopf New York.

[4] Waters, J. T., Marzano, R. J., \& McNulty, B. (2004). Leadership that sparks learning. Educational leadership, 61(7), 48.

[5] Grady, M. L., \& LeSourd, S. J. (1989). Principals' attitudes toward visionary leadership. The High School Journal, 73(2), 103-110.

[6] Lesourd, S. J., Tracz, S., \& Grady, M. L. (1992). Attitude Tpward Visionary Leadership. Journal of School Leadership, 2(1), 34-44.

[7] M. Taylor, C., J. Cornelius, C., \& Colvin, K. (2014). Visionary leadership and its relationship to organizational effectiveness. Leadership \& Organization Development Journal, 35(6), 566-583.

[8] Valenzuela, K. (2007). Leadership Definisions. NY: Prentice Hall.

[9] Tepsaeng, S. (2009). Visionary Leadership: New Model of School Administrators in Next Decade. Journal of Educational Administration, Srinagarinwirote University, 6(11), 83-95. 
[10] Bennis, W. (1997). Managing People Is Like Herding Cats: The point is that cats won't be herded. Executive Exellence, 14, 20-20.

[11] Ancona, D., Malone, T. W., Orlikowski, W. J., \& Senge, P. M. (2009). In praise of the incomplete leader. Leadership, 108.

[12] Johnson, J., Joseph F, \& Uline, C. L. (2005). Preparing educational leaders to close achievement gaps. Theory into practice, 44(1), 45-52.

[13] LeSourd, S. J., \& Grady, M. L. (1989). Visionary attributes in principals' descriptions of their leadership. The High School Journal, 73(2), 111-117.

[14] Prasertrattana, S. (2012). A Structural Equation Model of Distributed Leadership for Basic School Administrators. PhD Thesis, Khon Kaen: Khon Kaen University.

[15] Nanus, B. (1992a). Visionary Leadership: Creating a Compelling Sense of Direction for Your Organization: ERIC.

[16] Peredia, M. J. (2009). Leadership practices of principals in high-achieving Title I, K-8 schools: University of La Verne.

[17] Blumberg, A., \& Greenfield, W. (1986). The effective principal: Perspectives on school leadership: ERIC.

[18] Lawrence-Lightfoot, S. (2008). The good high school: Portraits of character and culture: Basic Books.

[19] Mokhtari, K., Thoma, J., \& Edwards, P. (2009). How one elementary school uses data to help raise students' reading achievement. The Reading Teacher, 63(4), 334-337.

[20] Bennis, W., \& Nanus, B. (1985). The strategies for taking charge. Leaders, New York: Harper. Row, 41.

[21] Deal, T. E., \& Kennedy, A. A. (1983). Corporate cultures: The rites and rituals of corporate life: Addison-Wesley, 1982. ISBN: 0-201-10277-3. \$14.95. Business Horizons, 26(2), 82-85.

[22] Kottkamp, R. B. (1984). The Principal as Cultural Leader. Planning and Changing, 15(3), 152-160.

[23] Bredeson, P. V. (1985). An analysis of the metaphorical perspectives of school principals. Educational Administration Quarterly, 21(1), 29-50.

[24] Wolcott, H. F. (2003). Teachers versus technocrats: An educational innovation in anthropological perspective: Rowman Altamira.

[25] Kananurak, N. (2011). Leadership role for producing professional employees. University of the Thai Chamber of Commerce Journal, 31(1).

[26] Powe, K. (1992). Visionary Leadership and the Waves of the Future. Updating School Board Policies, 23(8), 1-3.

[27] Robinson, V. M. (2006). Putting education back into educational leadership. Leading and managing, 12(1), 62.

[28] Thomas, G. (2005). Elementary principal emotional intelligence, leadership behaviour, and opennes: An exploratory study (Ph.D. dissertation, Department of Management in Organizational Leadership, University of Ohio State, U.S.A.).

[29] Kahan, S. (2008). Visionary Leadership: Motivational Speaker: Retrieved from http//: www. sethkahan. com/Resources_Ovisionary_leadership. html.

[30] Kapu, S. (2008). Principles of Visonary Leadership. Retrieved March, 12, 2008.

[31] Nanus, B. (1992b). Visionary leadership: how to re-vision the future. The Futurist, 26(5), 20.

[32] Tichy, N. M., \& Cohen, E. (1997). The leadership engine: HarperCollins New York.

[33] Mariasse, A. L. (1985). Vision and leadership: Paying attention to intention. Peabody Journal of Education, 63(1), 150-173. 
[34] Zaid, M. (2006). Visionary leadership and organizational effectiveness in institutions of higher learning.

[35] Prasetya, A. (2019). School of Visionary Leadership in Developing Characters of Students. In 3rd International Conference on Education Innovation (ICEI 2019). Atlantis Press.

[36] Butt, M. (1994). What do superintendents do to turn vision into action? A biography of pragmatic visionaries.

[37] Chansiri, W. (2008). Developing Core Competencies of Supporting-Line Administrators at Public Universities. Graduate Theses and Dissertations.

[38] Thompson, S. (2009). Visionary Leadership in Action while there is More to Leadership than Vision: Retrieved from http//: www. books. google. co. th/books.

[39] Lee, M., \& Wong. A. (2006). Paper for Presenting on ASEAN New Wave Leadership Development Training Program. Singapore: CSC.

[40] Rausch, E., Elmuti, D., Minnis, W., \& Abebe, M. (2005). Does education have a role in developing leadership skills? Management Decision.

[41] Sashkin, M. (1996). Becoming a visionary leader. Amherst, MA: HRD Press. ics, 13, 2640.

[42] Sashkin, M. (1992). Strategic leadership competencies.

[43] Sashkin, M., \& Sashkin, M. G. (2003). Leadership that matters: The critical factors for making a difference in people's lives and organizations' success: Berrett-Koehler Publishers.

[44] Crosby, B. C., \& Bryson, J. M. (2010). Leading across frontiers: how visionary leaders integrate people, processes, structures and resources The New Public Governance? (pp. 216-238): Routledge.

[45] Dvir, T., Eden, D., Avolio, B. J., \& Shamir, B. (2002). Impact of transformational leadership on follower development and performance: A field experiment. Academy of management journal, 45(4), 735-744.

[46] Lührmann, T., \& Eberl, P. (2007). Leadership and identity construction: Reframing the leader-follower interaction from an identity theory perspective. Leadership, 3(1), 115127

[47] Zhu, X. J. (2005). Semi-supervised learning literature survey: University of WisconsinMadison Department of Computer Sciences.

[48] Avolio, B. J., Waldman, D. A., \& Yammarino, F. J. (1991). Leading in the 1990s: The four I' s of transformational leadership. Journal of European industrial training.

[49] Hariri, H., Ridwan, \& Karwan, D. H. (2016). Manajemen Pendidikan. Yogyakarta: Media Akademi.

[50] Karwan, D. H., Hariri, H., \& Ridwan, R. (2020). Principal Visionary Leadership in Public Junior High Schools in Lampung, Indonesia. Jurnal Pendidikan Progresif, 10(1), $1-10$.

[51] Dinham, S., Cairney, T., Craigie, D., \& Wilson, S. (1995). School climate and leadership: Research into three secondary schools. Journal of Educational Administration.

[52] Catano, N., \& Stronge, J. H. (2006). What are principals expected to do? Congruence between principal evaluation and performance standards. NASSP bulletin, 90(3), 221237.

[53] Hallinger, P., Bickman, L., \& Davis, K. (1996). School context, principal leadership, and student reading achievement. The Elementary School Journal, 96(5), 527-549. 
[54] Manning, T., \& Robertson, B. (2002). The dynamic leader-leadership development beyond the visionary leader. Industrial and commercial training.

[55] Robinson, V. M., Lloyd, C. A., \& Rowe, K. J. (2008). The impact of leadership on student outcomes: An analysis of the differential effects of leadership types. Educational Administration Quarterly, 44(5), 635-674.

[56] Wolcott, H. F. (1994). The elementary school principal: Notes from a field study. Transforming qualitative data: Description, analysis, and interpretation, 115-148.

[57] Luyten, H., Visscher, A., \& Witziers, B. (2005). School effectiveness research: From a review of the criticism to recommendations for further development. School effectiveness and school improvement, 16(3), 249-279.

[58] Mora-Whitehurst, R. (2013). The relationship between elementary principals' visionary leadership and students' reading performance. Paper presented at the The Educational Forum.

[59] Hallinger, P., \& Heck, R. H. (1996). Educational Administration Quarterlxm. Educational Administration Quarterly, 32(1), 5-44.

[60] Starratt, R. J. (1995). Leaders with vision: The quest for school renewal: ERIC.

[61] Rosenholtz, S. J. (1985). Effective schools: Interpreting the evidence. American journal of Education, 93(3), 352-388.

[62] Yordsala, S., Tesaputa, K., \& Sri-Ampai, A. (2014). The development of visionary leadership administrators in thai primary school. International Education Studies, 7(1), 92-101.

[63] Murphy, J. (1990). Principal instructional leadership. Advances in educational administration: Changing perspectives on the school, 1(Part B), 163-200.

[64] Shamir, B., House, R. J., \& Arthur, M. B. (1993). The motivational effects of charismatic leadership: A self-concept based theory. Organization science, 4(4), 577-594.

[65] Colton, D. L. (1985). Vsion. National Forum, 65(2), pp. 33-35.

[66] Jul-Chan, C., \& Colin, S.,. (2004). Leadership effectiveness, leadership style and employee readiness. . Leadership and Organizational Development Journal,, 26(4), pp. 280-288.

[67] Greenfield, T., \& Ribbins, P. (2005). Greenfield on educational administration: Towards a humane craft: Routledge.

[68] Barth, R. S. (1986). The principal and the profession of teaching. The Elementary School Journal, 86(4), 471-492.

[69] Puangnil, T. (2012). Strategic leadership development program for school Principals in Basic Education Commission. Ph. D. Thesis (Education.

[70] Ylimaki, R. M. (2006). Toward a new conceptualization of vision in the work of educational leaders: Cases of the visionary archetype. Educational Administration Quarterly, 42(4), 620-651. 